\title{
DYNAMICS AND STABILITY OF A FLEXIBLE, SLENDER CYLINDER FLEXIBLY RESTRAINED AT ONE END AND FREE AT THE OTHER AND SUBJECTED TO AXIAL FLOW
}

\begin{abstract}
In this paper, Lagrange's equations along with the Ritz method are used to obtain the equation of motion for a flexible, slender cylinder subjected to axial flow. The cylinder is supported only by a translational and a rotational spring at the upstream end, and at the free end, it is terminated by a tapering end-piece. The equation of motion is solved numerically for a system in which the translational spring is infinitely stiff, thus acting as a pin, while the stiffness of the rotational spring is generally non-zero. The dynamics of such a system with the rotational spring of an average stiffness is described briefly. Moreover, the effects of the length of the cylinder and the shape of the end-piece on the critical flow velocities and the modal shapes of the unstable modes are investigated.
\end{abstract}

\section{Introduction}

Since the study by Hawthorne [1] in the late 1950s on the dynamics of the Dracone, a flexible sausage-like container towed behind a small vessel, the dynamics and stability of flexible slender structures subjected to axial flow have been studied extensively by applied mechanics researchers; some examples are the studies by Païdoussis [2-4] on the dynamics of flexible cylinders in axial flow with various boundary conditions, the studies by Triantafyllou and Chryssostomidis [5,6] on the dynamics of a cantilevered beam and a pinned-free string subjected to axial flow, and those by Dowling $[7,8]$ on the dynamics of neutrally and negatively buoyant elements of a towed system; for a comprehensive review of these studies, see [9].

\footnotetext{
${ }^{1}$ Department of Mechanical Engineering, McGill University, 817 Sherbrooke Street West, Montreal, QC, Canada H3A 0C3 Email: mojtaba.kheiri@mail.mcgill.ca
} 
It is now well-known that a flexible cylinder (cantilevered or with both ends supported) in axial flow, for sufficiently high flow velocities, may be subject to static divergence (buckling) in its first mode and to oscillatory instabilities (i.e. flutter) in higher flexural modes. A towed flexible cylinder, on the other hand, is generally prone to both rigid-body and flexural instabilities, the former occurring at relatively low towing speeds, while the latter develop at higher towing speeds.

Some new theoretical/experimental developments have taken place in the recent decade in connection with the study of the dynamics of flexible slender structures in axial flow. For example, Modarres-Sadeghi et al. [10] developed a nonlinear model for an extensible flexible cylinder subjected to axial flow and analyzed the dynamics of such a system. In a paper by de Langre et al. [11], it was shown that, contrary to previous predictions made via simplified models (e.g. those presented in [6] and [7]), divergence and flutter may arise for thin, very long cylinders, provided that the free downstream end of the cylinder is well-streamlined. Rinaldi and Païdoussis [12] investigated the dynamics of a free-clamped cylinder (i.e. flow is directed from the free end toward the clamped one) in confined axial air-flow theoretically and experimentally.

Most recently, a nonlinear model was developed for the dynamics of towed flexible cylinders [13]; the existence of rigid-body as well as flexural instabilities was proved, in general qualitative agreement with experimental observations. In a two-part paper [14, 15], Kheiri et al. investigated the dynamics of long pipelines towed underwater with a configuration used in deep ocean storage of liquid $\mathrm{CO}_{2}$. It was found that, for long pipelines, both divergence and flutter may arise in the course of motion, thus confirming the results obtained by de Langre et al. [11]; it was also found that the onset of these instabilities is weakly dependent on the length of the pipeline.

Moreover, Kheiri et al. [16] conducted a new set of experiments in a water tunnel with flexible cylinders to illustrate the dynamical behaviour of towed flexible cylinders and to test the recently developed nonlinear theory [13]. The dynamics and stability of a pinned-free cylinder in axial flow were investigated by Kheiri and Païdoussis [17]. It was shown that the system loses stability by stationary yawing (i.e. a divergent non-oscillatory deviation from the position of rest, with or without flexing) at essentially zero flow velocity, provided that the free downstream end of the cylinder is not very blunt. At higher flow velocities, static/dynamic instabilities in the first and higher modes of the system may occur.

In this paper, a theoretical model is presented for the dynamics of a flexible, slender cylinder flexibly supported (i.e. spring-supported) at its upstream end and free downstream. It is, in fact, of fundamental importance to study the change in dynamical behaviour of the system as the stiffness of the support 
is varied. This is also important from practical point of view, as in real-world cases, there is almost no perfect clamped or pinned end boundary conditions. Here, the primary focus is on the study of the dynamics of a pinned-free flexible cylinder, additionally supported at the pinned end by a rotational spring.

\section{Theory}

\subsection{Definitions and preliminaries}

See Fig. 1 which shows a flexible cylinder of length $L$ and cross-sectional area $A$ (i.e., $A=\pi D^{2} / 4$, where $D$ is the cylinder diameter). The cylinder is supported at one end by a translational and a rotational spring, the stiffnesses of which are, respectively, $k_{0}$ and $c_{0}$, and is free at the other. At the free end, the cylinder is fitted with a rigid tapering end-piece of length $\ell(\ell \ll L)$. The body is immersed in an incompressible fluid of density $\rho$ flowing with uniform velocity $U$ parallel to the $x$-axis, which coincides with the position of rest of the body. Except for the tapering end-piece, the body is of constant mass per unit length $m$ and flexural rigidity $E I$.

It is fairly reasonable to assume that the axial strain in the centreline of the cylinder shown in Fig. 1 is negligible, i.e. the inextensibility condition. ${ }^{1}$ It is further assumed that the body is neutrally buoyant (i.e. the average density of the body is close to $\rho$ ), thus the forces due to gravity and buoyancy do not come into play, and the motions are considered to take place within the $(x, y)$-plane, which for the sake of simplicity is assumed to be horizontal.

For non-conservative continuous systems such as the one in Fig. 1, the equation of motion is commonly obtained using the extended Hamilton's principle. The equation of motion in the form of a partial differential equation is then discretized using, for example, Galerkin's method (see, e.g., [13, 18]). However, as noted in [19], a more versatile method to obtain the discretized equations is using the Lagrange equations. More precisely, in this method, an approximate solution is considered based on the Ritz method; with this solution, the expressions of energy of the system and virtual work are approximated (i.e. discretized), and by substituting them in the Lagrange equations, the discretized equations of motion are obtained.

The Lagrange equations can be written as

$$
\frac{\mathrm{d}}{\mathrm{d} t}\left(\frac{\partial \mathcal{T}}{\partial \dot{q}_{i}}\right)-\frac{\partial \mathcal{T}}{\partial q_{i}}+\frac{\partial \mathcal{V}}{\partial q_{i}}=Q_{i}, \quad i=1, \cdots, N
$$

\footnotetext{
${ }^{1}$ In other words, the distance between two arbitrary points on the centreline remains constant before and after deformation.
} 


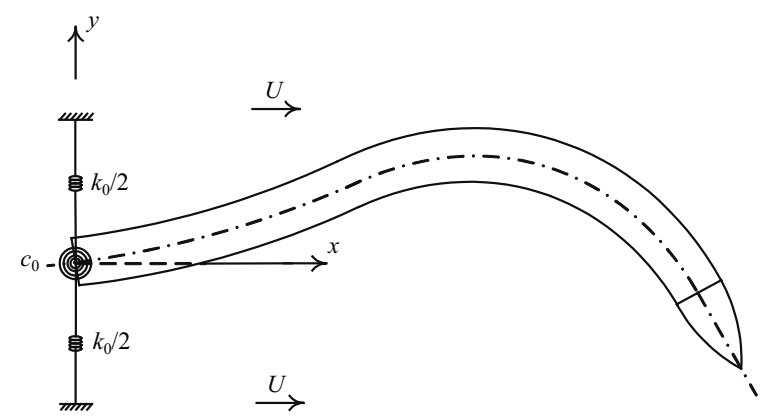

Fig. 1. A flexible cylinder subjected to axial flow of uniform velocity $U$ and supported only at the upstream end by a translational and a rotational spring, the stiffnesses of which are represented, respectively, by $k_{0}$ and $c_{0}$.

where $\mathcal{T}$ and $\mathcal{V}$ are the kinetic and potential energies of the system, respectively; $q_{i}$ and $Q_{i}$ are the generalized coordinates and forces, respectively; also, $t$ is time and $N$ number of degrees of freedom.

The approximate solution based on the Ritz method for the problem in hand may be written as

$$
y(s, t)=\sum_{j=1}^{N} \phi_{j}(s) q_{j}(t),
$$

where $y$ is the displacement of the cylinder in the transverse direction and $s$ the curvilinear coordinate along the cylinder centreline; also, $\phi_{j}(s)$ are suitable basis functions or assumed modes (here, we use the free-free Euler-Bernoulli beam eigenfunctions as basis functions; see [13] for the expressions of these eigenfunctions).

\subsection{Kinetic and potential energies of the system}

For an element $\delta s$ of the cylinder, the kinetic and potential energies, represented by $\mathcal{T}_{c}$ and $\mathcal{V}_{c}$, respectively, may be written as

$$
\mathcal{T}_{c}=\frac{1}{2} \int_{0}^{L} m\left[\left(\frac{\partial x}{\partial t}\right)^{2}+\left(\frac{\partial y}{\partial t}\right)^{2}\right] \mathrm{d} s, \quad \mathcal{V}_{c}=\frac{1}{2} \int_{0}^{L} E I \bar{\kappa}^{2} \mathrm{~d} s,
$$

where $\bar{\kappa}$ is the curvature of the neutral axis of the cylinder. ${ }^{2}$ Here, the potential energy includes only the strain energy due to cylinder bending. Also, it is recalled that $x$ and $y$ are the coordinates of the element in a system associated with the deformed body.

\footnotetext{
${ }^{2}$ For a beam with inextensible axis, it can be shown that $\bar{\kappa}=\left(\partial^{2} y / \partial s^{2}\right) /\left(1-(\partial y / \partial s)^{2}\right)^{1 / 2}$.
} 
Similarly, the kinetic and potential energies of the end-piece are written as

$$
\mathcal{T}_{e p}=\frac{1}{2} \int_{L}^{L+\ell} \rho_{e p} A(s)\left[\left(\frac{\partial x}{\partial t}\right)^{2}+\left(\frac{\partial y}{\partial t}\right)^{2}\right] \mathrm{d} s, \mathcal{V}_{e p}=0,
$$

where $\rho_{e p}$ is the mass density of the end-piece, which is assumed to be equal to that of the cylinder; $A(s)$ is the local cross-sectional area; $\mathcal{V}_{e p}$ is zero in absence of gravity forces, and because the end-piece is considered rigid.

It should be noted that for the end-piece, unlike the cylinder, $D(s)$ and $A(s)$ are not constant. Also, it is assumed that the end-piece is sufficiently short, so that $y$ and its derivatives may be considered constant over its length.

The potential energy associated with the end-springs, $\mathcal{V}_{s p}$, is

$$
\mathcal{V}_{s p}=\left.\frac{1}{2} k_{0} y^{2}\right|_{s=0}+\left.\frac{1}{2} c_{0}\left(\frac{\partial y}{\partial s}\right)^{2}\right|_{s=0} .
$$

Thus, expressions of the kinetic and potential energies of the system (i.e. the total kinetic and potential energies) in discretized form may be written as

$$
\begin{aligned}
& \mathcal{T}=\sum_{k=1}^{N} \sum_{j=1}^{N}\left[\frac{1}{2} m L \delta_{k j}+\frac{1}{2} m s_{e} \phi_{k}(L) \phi_{j}(L)\right] \dot{q}_{k} \dot{q}_{j} \\
& \mathcal{V}=\sum_{k=1}^{N} \sum_{j=1}^{N}\left[\frac{1}{2}(E I) L \lambda_{j}^{4} \delta_{k j}+\frac{1}{2} k_{0} \phi_{k}(0) \phi_{j}(0)+\frac{1}{2} c_{0} \phi_{k}^{\prime}(0) \phi_{j}^{\prime}(0)\right] q_{k} q_{j},
\end{aligned}
$$

in which the prime stands for $\partial() / \partial s$, and the overdot denotes a time derivative; also, the orthonormality of the eigenfunctions, i.e. $\int_{0}^{L} \phi_{k} \phi_{j} \mathrm{~d} s=L \delta_{k j}, \delta_{k j}$ being Kronecker's delta, and the fact that $\phi_{j}^{\prime \prime \prime \prime}=\lambda_{j}^{4} \phi_{j}, \lambda_{j}$ being the $j$ th eigenvalue of the free-free beam, have been utilized; moreover,

$$
s_{e}=\frac{1}{A} \int_{L}^{L+\ell} A(s) \mathrm{d} s .
$$

From equations (6) and (7), one can write

$$
\begin{aligned}
\frac{\partial \mathcal{T}}{\partial \dot{q}_{i}} & =\sum_{j=1}^{N}\left[m L \delta_{i j}+m s_{e} \phi_{i}(L) \phi_{j}(L)\right] \dot{q}_{j}, \quad \frac{\partial \mathcal{T}}{\partial q_{i}}=0, \\
\frac{\partial \mathcal{V}}{\partial q_{i}} & =\sum_{j=1}^{N}\left[(E I) L \lambda_{j}^{4} \delta_{i j}+k_{0} \phi_{i}(0) \phi_{j}(0)+c_{0} \phi_{i}^{\prime}(0) \phi_{j}^{\prime}(0)\right] q_{j} .
\end{aligned}
$$




\subsection{Virtual work and generalized forces}

The virtual work $\delta \mathcal{W}_{c}$ due to the fluid-dynamic forces acting on the cylinder may be written as (see Fig. 2a)

$$
\begin{aligned}
\delta \mathcal{W}_{c}= & \int_{0}^{L}\left\{\left[F_{L} \cos \theta+\left(F_{A}+F_{N}\right) \sin \theta\right] \delta x+\right. \\
& \left.+\left[F_{L} \sin \theta-\left(F_{A}+F_{N}\right) \cos \theta\right] \delta y\right\} \mathrm{d} s,
\end{aligned}
$$

where $F_{L}$ and $F_{N}$ are the viscous forces per unit length in the longitudinal and normal direction, respectively; $F_{A}$ is the inviscid hydrodynamic force per unit length; $\theta$ is the angle between the centreline of the deformed cylinder and the $x$-axis; also, $\delta x$ and $\delta y$ are the virtual displacements in the $x$ - and $y$-direction, respectively.

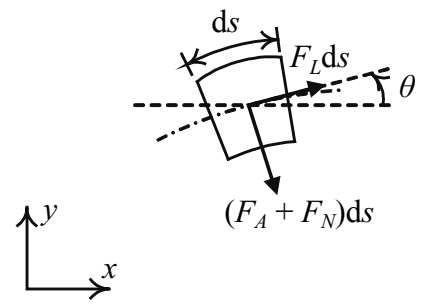

(a)

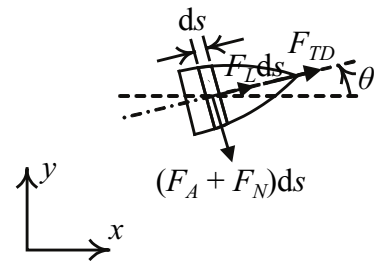

(b)

Fig. 2. a) An infinitesimal element $\mathrm{d} s$ of the cylinder showing the external forces acting on it; b) The external forces acting on the tapering end-piece

The viscous forces $F_{L}$ and $F_{N}$ are obtained using expressions proposed by Taylor [20] for 'rough cylinders', where the roughness is considered as a number of long projections pointing equally in all directions; these expressions are

$$
F_{L}=\frac{1}{2} \rho D U^{2} C_{f} \cos i, \quad F_{N}=\frac{1}{2} \rho D U^{2}\left(C_{f} \sin i+C_{D p} \sin ^{2} i\right),
$$

where $C_{f}$ and $C_{D p}$ are the coefficients associated with frictional and form drag, respectively; $i$ is the angle of incidence, which is defined as the angle between the relative fluid-body velocity and the axis of the cylinder (i.e. $i=$ $=\tan ^{-1}(\partial y / \partial x)+\tan ^{-1}[(\partial y / \partial t) / U]$, where $(\partial x / \partial t)$ has been ignored $)$.

For small $i$, equation (11) may be linearized as (refer to [9])

$$
F_{L}=\frac{1}{2} \rho D U^{2} C_{T}, \quad F_{N}=\frac{1}{2} \rho D U C_{N}\left(\frac{\partial y}{\partial t}+U \frac{\partial y}{\partial x}\right)+\frac{1}{2} \rho D C_{D} \frac{\partial y}{\partial t},
$$


where it is assumed that the friction drag coefficients in the longitudinal and normal directions are not necessarily equal; they are represented by $C_{T}$ and $C_{N}$, respectively. The second term in $F_{N}$ represents the linearized form drag.

The inviscid hydrodynamic force $F_{A}$ is obtained using slender-body theory (refer to [21] for details)

$$
F_{A}=\left(\frac{\partial}{\partial t}+U \frac{\partial}{\partial s}\right)[M(s) V(s, t)] .
$$

where $V(s, t)=(\partial y / \partial t)+U(\partial y / \partial s)$ is the relative lateral velocity between the cylinder and flow, and $M(s)=\rho A(s)$ is the 'virtual' or 'added' mass of the fluid per unit length.

Similarly, the virtual work associated with the fluid-related forces acting on the end-piece is written as (see Fig. 2b)

$$
\begin{aligned}
\delta \mathcal{W}_{e p}= & \int_{L}^{L+\ell}\left\{\left[F_{L} \cos \theta+\left(f F_{A}+F_{N}\right) \sin \theta\right] \delta x+\right. \\
& \left.+\left[F_{L} \sin \theta-\left(f F_{A}+F_{N}\right) \cos \theta\right] \delta y\right\} \mathrm{d} s+ \\
& +\left(F_{T D} \cos \theta\right) \delta x+\left(F_{T D} \sin \theta\right) \delta y,
\end{aligned}
$$

in which all quantities, except for $D(s)$ and $A(s)$, are evaluated at $s=L$, i.e. $\delta x=\left.\delta x\right|_{s=L}, \theta=\left.\theta\right|_{s=L}$ etc. Thus, the expressions for $F_{L}, F_{N}$ and $F_{A}$ over the end-piece can easily be obtained from equations (12) and (13); they can alternatively be obtained as in [18].

As seen from equation (14), the inviscid hydrodynamic force per unit length over the end-piece is $f F_{A}$, where $f$ accounts for departures from ideal inviscid hydrodynamic theory (slender-body theory) over the end-piece (see [9]); the parameter $f$ is normally between 0 and 1 : for a perfectly streamlined end-piece, $f \rightarrow 1$, whereas for a perfectly blunt end-piece, $f \rightarrow 0$.

In equation (14), $F_{T D}$ is the form drag over the end-piece in the longitudinal direction. This force in its linear form may be expressed as

$$
F_{T D}=\frac{1}{2} \rho D^{2} U^{2} C_{T D}
$$

where $C_{T D}$ is the form-drag coefficient for the end-piece, which in dimensionless form is usually linked to $f$, as discussed in [13].

To simplify equations (10) and (14), one may use the following relationship between virtual displacements $\delta x$ and $\delta y$ (refer to [22]):

$$
\delta x=y_{0}^{\prime} \delta y_{0}-y^{\prime} \delta y+\int_{0}^{s} y^{\prime \prime} \delta y \mathrm{~d} s,
$$


where the subscript 0 signifies the quantity concerned at $s=0$.

Thus, using equations (2) and (16), $\delta \mathcal{W}_{c}$ and $\delta \mathcal{W}_{e p}$ are rewritten as

$$
\begin{aligned}
\delta \mathcal{W}_{c}= & \sum_{i=1}^{N} \sum_{j=1}^{N}\left[\frac{1}{2} \rho D U^{2} C_{T} L \phi_{i}(0) \phi_{j}^{\prime}(0) q_{j}-M L \delta_{i j} \ddot{q}_{j}-2 M U b_{i j} \dot{q}_{j}+\right. \\
& -\frac{M U^{2}}{L} c_{i j} q_{j}-\frac{1}{2} \rho D U C_{N} L \delta_{i j} \dot{q}_{j}-\frac{1}{2} \rho D U^{2} C_{N} b_{i j} q_{j}+ \\
& \left.-\frac{1}{2} \rho D C_{D} L \delta_{i j} \dot{q}_{j}+\frac{1}{2} \rho D U^{2} C_{T} c_{i j} q_{j}-\frac{1}{2} \rho D U^{2} C_{T} d_{i j} q_{j}\right] \delta q_{i},
\end{aligned}
$$

and

$$
\begin{aligned}
\delta \mathcal{W}_{e p}= & \sum_{i=1}^{N} \sum_{j=1}^{N}\left[\frac{1}{2} \rho D U^{2} C_{T} \bar{s}_{e} \phi_{i}(0) \phi_{j}^{\prime}(0) q_{j}+\frac{1}{2} \rho D U^{2} C_{T} \frac{\bar{s}_{e}}{L} c_{i j} q_{j}+\right. \\
& -\frac{1}{2} \rho D U C_{N} \bar{s}_{e} \phi_{i}(L) \phi_{j}(L) \dot{q}_{j}-\frac{1}{2} \rho D U^{2} C_{N} \bar{s}_{e} \phi_{i}(L) \phi_{j}^{\prime}(L) q_{j}+ \\
& -\frac{1}{2} \rho D C_{D} \bar{s}_{e} \phi_{i}(L) \phi_{j}(L) \dot{q}_{j}-f M s_{e} \phi_{i}(L) \phi_{j}(L) \ddot{q}_{j}+ \\
& -f M s_{e} U \phi_{i}(L) \phi_{j}^{\prime}(L) \dot{q}_{j}+f M U \phi_{i}(L) \phi_{j}(L) \dot{q}_{j}+ \\
& +f M U^{2} \phi_{i}(L) \phi_{j}^{\prime}(L) q_{j}+\frac{1}{2} \rho D^{2} U^{2} C_{T D} \phi_{i}(0) \phi_{j}^{\prime}(0) q_{j}+ \\
& \left.+\frac{1}{2} \rho D^{2} U^{2} C_{T D} \frac{1}{L} c_{i j} q_{j}\right] \delta q_{i}
\end{aligned}
$$

respectively, in which $b_{i j}=\int_{0}^{L} \phi_{i} \phi_{j}^{\prime} \mathrm{d} s, c_{i j}=L \int_{0}^{L} \phi_{i} \phi_{j}^{\prime \prime} \mathrm{d} s$ and $d_{i j}=$ $=\int_{0}^{L} s \phi_{i} \phi_{j}^{\prime \prime} \mathrm{d} s ;$ also, $\bar{s}_{e}=(1 / D) \int_{L}^{L+\ell} D(s) \mathrm{d} s^{3}$

From equations (17) and (18), and considering the fact that $\delta \mathcal{W}_{c}+\delta \mathcal{W}_{e p}=$ $\sum_{i=1}^{N} Q_{i} \delta q_{i}$, the expression of generalized forces $Q_{i}$ becomes:

\footnotetext{
${ }^{3}$ We have also used the fact that $x \simeq s$, as it is assumed that the centreline of the cylinder is inextensible, and only linear terms are retained in the derivations.
} 


$$
\begin{aligned}
Q_{i}= & \sum_{j=1}^{N}\left\{-\left[M L \delta_{i j}+f M s_{e} \phi_{i}(L) \phi_{j}(L)\right] \ddot{q}_{j}-\left[2 M U b_{i j}+\frac{1}{2} \rho D U C_{N} L \delta_{i j}+\right.\right. \\
& +\frac{1}{2} \rho D C_{D} L \delta_{i j}+\frac{1}{2} \rho D U C_{N} \bar{s}_{e} \phi_{i}(L) \phi_{j}(L)+\frac{1}{2} \rho D C_{D} \bar{s}_{e} \phi_{i}(L) \phi_{j}(L)+ \\
& \left.+f M s_{e} U \phi_{i}(L) \phi_{j}^{\prime}(L)-f M U \phi_{i}(L) \phi_{j}(L)\right] \dot{q}_{j}-\left[\frac{1}{2} \rho D U^{2} C_{N} b_{i j}+\right. \\
& -\frac{1}{2} \rho D U^{2} C_{T} \frac{\bar{s}_{e}}{L} c_{i j}-\frac{1}{2} \rho D U^{2} C_{T}\left(c_{i j}-d_{i j}\right)-\frac{1}{2} \rho D^{2} U^{2} C_{T D} \frac{1}{L} c_{i j}+ \\
& +\frac{M U^{2}}{L} c_{i j}-\frac{1}{2} \rho D U^{2} C_{T}\left(L+\bar{s}_{e}\right) \phi_{i}(0) \phi_{j}^{\prime}(0)-\frac{1}{2} \rho D^{2} U^{2} C_{T D} \phi_{i}(0) \phi_{j}^{\prime}(0)+ \\
& \left.\left.-f M U^{2} \phi_{i}(L) \phi_{j}^{\prime}(L)+\frac{1}{2} \rho D U^{2} C_{N} \bar{s}_{e} \phi_{i}(L) \phi_{j}^{\prime}(L)\right] q_{j}\right\} .
\end{aligned}
$$

\subsection{The equation of motion}

By substituting equations (8), (9) and (19) into equation (1), the discretized equations of motion yield:

$$
\begin{aligned}
\sum_{j=1}^{N}\{ & {\left[(m+M) L \delta_{i j}+(m+f M) s_{e} \phi_{i}(L) \phi_{j}(L)\right] \ddot{q}_{j}+\left[2 M U b_{i j}+\right.} \\
& +\frac{1}{2} \rho D U C_{N} L \delta_{i j}+\frac{1}{2} \rho D C_{D} L \delta_{i j}+\frac{1}{2} \rho D U C_{N} \bar{s}_{e} \phi_{i}(L) \phi_{j}(L)+ \\
& \left.+\frac{1}{2} \rho D C_{D} \bar{s}_{e} \phi_{i}(L) \phi_{j}(L)+f M s_{e} U \phi_{i}(L) \phi_{j}^{\prime}(L)-f M U \phi_{i}(L) \phi_{j}(L)\right] \dot{q}_{j}+ \\
& +\left[(E I) L \lambda_{j}^{4} \delta_{i j}+k_{0} \phi_{i}(0) \phi_{j}(0)+c_{0} \phi_{i}^{\prime}(0) \phi_{j}^{\prime}(0)+\frac{1}{2} \rho D U^{2} C_{N} b_{i j}+\right. \\
& -\frac{1}{2} \rho D U^{2} C_{T} \frac{\bar{s}_{e}}{L} c_{i j}-\frac{1}{2} \rho D U^{2} C_{T}\left(c_{i j}-d_{i j}\right)-\frac{1}{2} \rho D^{2} U^{2} C_{T D} \frac{1}{L} c_{i j}+ \\
& +\frac{M U^{2}}{L} c_{i j}-\frac{1}{2} \rho D U^{2} C_{T}\left(L+\bar{s}_{e}\right) \phi_{i}(0) \phi_{j}^{\prime}(0)+ \\
& -\frac{1}{2} \rho D^{2} U^{2} C_{T D} \phi_{i}(0) \phi_{j}^{\prime}(0)-f M U^{2} \phi_{i}(L) \phi_{j}^{\prime}(L)+ \\
& \left.\left.+\frac{1}{2} \rho D U^{2} C_{N} \bar{s}_{e} \phi_{i}(L) \phi_{j}^{\prime}(L)\right] q_{j}\right\}=0, \quad(i=1 \cdots N)
\end{aligned}
$$


The equations of motion may be rendered dimensionless through the use of

$$
\xi=\frac{s}{L}, \quad \eta=\frac{y}{L}, \quad \tau=\left(\frac{E I}{M+m}\right)^{1 / 2} \frac{t}{L^{2}}
$$

where the dimensionless transverse displacement $\eta$ is written as $\eta(\xi, \tau)=$ $=\sum_{j=1}^{N} \varphi_{j}(\xi) q_{j}(\tau)$, in which $\varphi_{j}(\xi) \equiv \phi_{j}(s)$.

The $i$ th dimensionless equation of motion is

$$
\begin{aligned}
\sum_{j=1}^{N}\{ & \left\{\delta_{i j}+[1+(f-1) \beta] \chi_{e} \varphi_{i}(1) \phi_{j}(1)\right] \ddot{q}_{j}+\left[2 u \beta^{1 / 2} b_{i j}+\frac{1}{2} \varepsilon c_{N} u \beta^{1 / 2} \delta_{i j}+\right. \\
& +\frac{1}{2} \varepsilon c \beta^{1 / 2} \delta_{i j}+\frac{1}{2} \varepsilon c_{N} u \beta^{1 / 2} \bar{\chi}_{e} \varphi_{i}(1) \varphi_{j}(1)+\frac{1}{2} \varepsilon c \beta^{1 / 2} \bar{\chi}_{e} \varphi_{i}(1) \phi_{j}(1)+ \\
& \left.+f \beta^{1 / 2} u \chi_{e} \varphi_{i}(1) \varphi_{j}^{\prime}(1)-f \beta^{1 / 2} u \phi_{i}(1) \phi_{j}(1)\right] \dot{q}_{j}+\left[\tilde{\lambda}_{j}^{4} \delta_{i j}+\right. \\
& +\kappa_{0} \varphi_{i}(0) \varphi_{j}(0)+\kappa_{0}^{*} \varphi_{i}^{\prime}(0) \varphi_{j}^{\prime}(0)+\frac{1}{2} \varepsilon c_{N} u^{2} b_{i j}-\frac{1}{2} \varepsilon c_{T} u^{2} \bar{\chi}_{e} c_{i j}+ \\
& -\frac{1}{2} \varepsilon c_{T} u^{2}\left(c_{i j}-d_{i j}\right)-\frac{1}{2} c_{b} u^{2} c_{i j}+u^{2} c_{i j}-\frac{1}{2} \varepsilon c_{T} u^{2}\left(1+\bar{\chi}_{e}\right) \varphi_{i}(0) \varphi_{j}^{\prime}(0)+ \\
& -\frac{1}{2} u^{2} c_{b} \varphi_{i}(0) \varphi_{j}^{\prime}(0)-f u^{2} \varphi_{i}(1) \varphi_{j}^{\prime}(1)+ \\
& \left.\left.+\frac{1}{2} \varepsilon c_{N} u^{2} \bar{\chi}_{e} \varphi_{i}(1) \varphi_{j}^{\prime}(1)\right] q_{j}\right\}=0,
\end{aligned}
$$

where from now on $\left({ }^{\circ}\right)=\partial() / \partial \tau$ and ()$^{\prime}=\partial() / \partial \xi$; also, $\delta_{i j}=\int_{0}^{1} \varphi_{i} \varphi_{j} \mathrm{~d} \xi$, $b_{i j}=\int_{0}^{1} \varphi_{i} \varphi_{j}^{\prime} \mathrm{d} \xi, c_{i j}=\int_{0}^{1} \varphi_{i} \varphi_{j}^{\prime \prime} \mathrm{d} \xi, d_{i j}=\int_{0}^{1} \xi \varphi_{i} \varphi_{j}^{\prime \prime}$ and $\tilde{\lambda}_{j}=\lambda_{j} L$.

The following dimensionless system parameters have also arisen:

$$
\begin{aligned}
& u=\left(\frac{M}{E I}\right)^{1 / 2} U L, \quad \beta=\frac{M}{M+m}, \quad \varepsilon=\frac{L}{D}, \quad c_{N}=\frac{4}{\pi} C_{N}, \\
& c_{T}=\frac{4}{\pi} C_{T}, \quad c_{b}=\frac{4}{\pi} C_{T D}, \quad c=\frac{4}{\pi}\left(\frac{M}{E I}\right)^{1 / 2} L C_{D}, \\
& \chi_{e}=\frac{s_{e}}{L}, \quad \bar{\chi}_{e}=\frac{\bar{s}_{e}}{L}, \quad \kappa_{0}=\frac{k_{0} L^{3}}{E I}, \quad \kappa_{0}^{*}=\frac{c_{0} L}{E I} .
\end{aligned}
$$

The above integrals for determining $b_{i j}, c_{i j}$ and $d_{i j}$ may either be computed numerically or found analytically. 


\section{Analysis}

By letting $\dot{\mathbf{q}}=\mathbf{u}$, where $\mathbf{q}=\left[\begin{array}{llll}q_{1} & q_{2} & \cdots & q_{N}\end{array}\right]^{\mathrm{T}}$, equation (22) is reduced to first-order or state-space form which is then transformed from the time domain to the frequency domain by assuming a harmonic solution (i.e., $\{\mathbf{u} \mathbf{q}\}^{\mathrm{T}}=$ $\left.=\{\overline{\mathbf{u}} \overline{\mathbf{q}}\}^{\mathrm{T}} \mathrm{e}^{\mathrm{i} \omega \tau}\right)$. Generally complex values of $\omega(\omega \equiv \mathcal{R} e(\omega)+\mathrm{i} \operatorname{Im}(\omega))$ are then obtained via an eigenvalue-problem solver, and their evolution with a system parameter, e.g. the dimensionless flow velocity $u$, is plotted in an Argand diagram. In the Argand diagram, the abscissa and the ordinate correspond to the real and imaginary parts of $\omega,(\mathcal{R} e(\omega)$ and $\operatorname{Im}(\omega))$, respectively. It is noted that $\operatorname{Re}(\omega)$ corresponds to the dimensionless oscillation frequency, while $\operatorname{Im}(\omega)$ is related to damping, i.e. the damping ratio is $\zeta=\operatorname{Im}(\omega) / \mathcal{R} e(\omega)$. Thus, $\operatorname{Im}(\omega)>0$ indicates stability, while $\operatorname{Im}(\omega)<0$ means instability; more specifically, instability materializes by the crossing of $\omega$ locus from the positive to the negative half-plane in the Argand diagram.

It is fairly easy to show that the translational spring will act as a pin if $\kappa_{0} \rightarrow \infty$; in fact, letting, for example, $\kappa_{0}=10^{10}$ in the numerical solution may reasonably simulate a pinned end. As mentioned previously, the focus in this paper is on the study of the dynamics of a pinned-free flexible cylinder, additionally supported at the pinned (upstream) end by a rotational spring of stiffness $\kappa_{0}^{*}$. It is interesting to see how the dynamical behaviour of the system changes as $\kappa_{0}^{*}$ is varied.

The dynamics of a typical pinned-free cylinder, additionally supported at the pinned end by a rotational spring of stiffness $\kappa_{0}^{*}=1$ and fitted at the free end with a fairly well streamlined end-piece $(f=0.7)$ is illustrated in Fig. 3 (see the caption for parameters). More specifically, this figure shows the evolution of the lowest three complex frequencies of the system as the dimensionless flow velocity $u$ is varied. As seen from the figure, all modes are stable at low flow velocities. For sufficiently high flow velocities, the frequency of the first and second modes successively become purely imaginary, bifurcating on the $\operatorname{Im}(\omega)$-axis. The arrows just off the $\operatorname{Im}(\omega)$-axis identify the points belonging to the loci of these modes evolving on the $\operatorname{Im}(\omega)$-axis. The frequency associated with one branch of each of these two modes eventually vanishes altogether, indicating the onset of static divergence (buckling).

The first divergence occurs at $u \simeq 1.2$, in the first mode, followed at $u \simeq 7.7$ by divergence in the second mode. But before the second-mode divergence occurs, the negative branch of the first mode becomes positive at $3.9<u<4.0$, and at a slightly higher $u$, this branch and the other positive branch of the first-mode locus coalesce and leave the $\operatorname{Im}(\omega)$-axis; shortly after, at $u \simeq 4.4$, the first-mode locus crosses from the positive to the negative half-plane, where $\operatorname{Re}(\omega) \neq 0$, indicating the onset of first-mode flutter. Before 


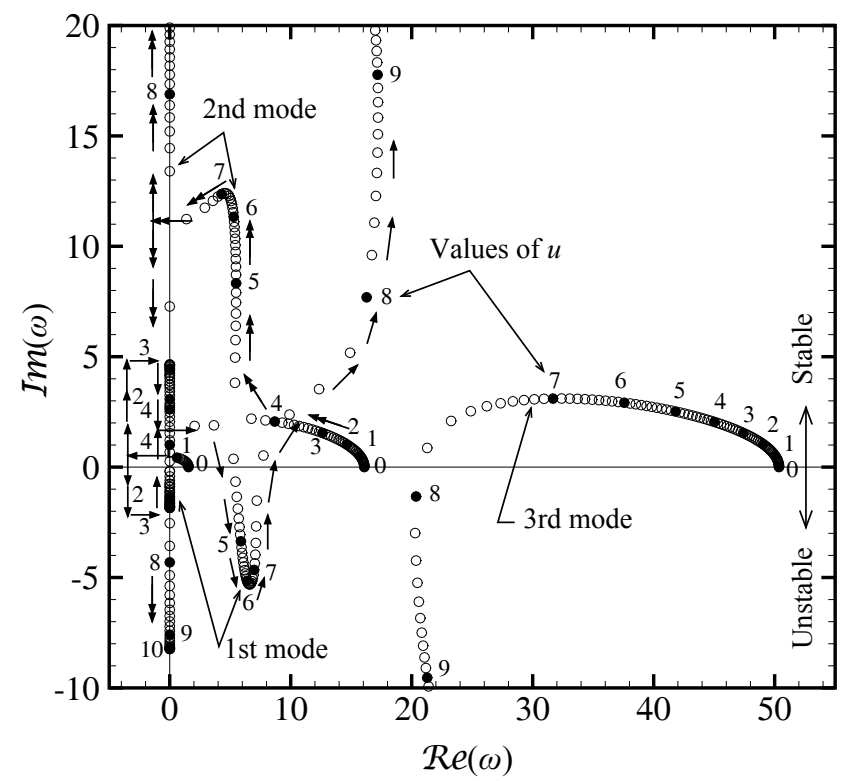

Fig. 3. Argand diagram of the complex frequencies, $\omega$, of the lowest three modes of a pinned-free cylinder with a rotational spring of stiffness $\kappa_{0}^{*}=1$ at the pinned end and a tapered free end ( $f=0.7)$ in axial flow, as a function of $u$; other parameters are: $\varepsilon c_{T}=\varepsilon c_{N}=0.5, c_{b}=1-f=0.3$, $\chi_{e}=0.00667, \bar{\chi}_{e}=0.00785$ and $c=0.0$. Arrows show the evolution of the first mode and two headed arrows the evolution of the second mode.

this flutter occurs, the system experiences a short interval of stability (i.e. $3.9<u<4.4$ ). Finally, third-mode flutter occurs at $u \simeq 8.0$.

\subsection{The effect of $\varepsilon c_{f}$ on the critical flow velocities and the modal shapes}

Fig. 4 shows the variation of the critical flow velocities for static and dynamic instabilities of a pinned-free cylinder, additionally supported at the pinned end by a rotational spring of stiffness $\kappa_{0}^{*}$, with different values of $\varepsilon c_{f}$ $\left(\varepsilon c_{f}=\varepsilon c_{T}=\varepsilon c_{N}\right)$ as a function of $\kappa_{0}^{*}$. Two different values of $\varepsilon c_{f}$ are considered, which are $\varepsilon c_{f}=0.5$ and $\varepsilon c_{f}=5.0$. In reality this could be achieved by having two cylinders of the same diameter and surface roughness but of different lengths (i.e. $L_{2} / L_{1}=10$, where $L_{1}$ and $L_{2}$ correspond to the cylinders with $\varepsilon c_{f}=0.5$ and $\varepsilon c_{f}=5.0$, respectively). It is noted that the values of critical flow velocities in Fig. 4 have been normalized such that they do not depend on $L$ and $D$ (i.e. $u_{c r}^{*}=u_{c r} / \varepsilon^{*}$, where $\varepsilon^{*}=(1 / 2) \varepsilon c_{f}$ ).

As seen from the figure, the cylinder with $\varepsilon c_{f}=0.5$ (cylinder 1, for short) becomes more stable as $\kappa_{0}^{*}$ takes on large values, whereas it is less stable as $\kappa_{0}^{*}$ takes on very small values. This is indeed very much expected since increasing $\kappa_{0}^{*}$ means a stronger upstream support, which delays instabilities, and vice 


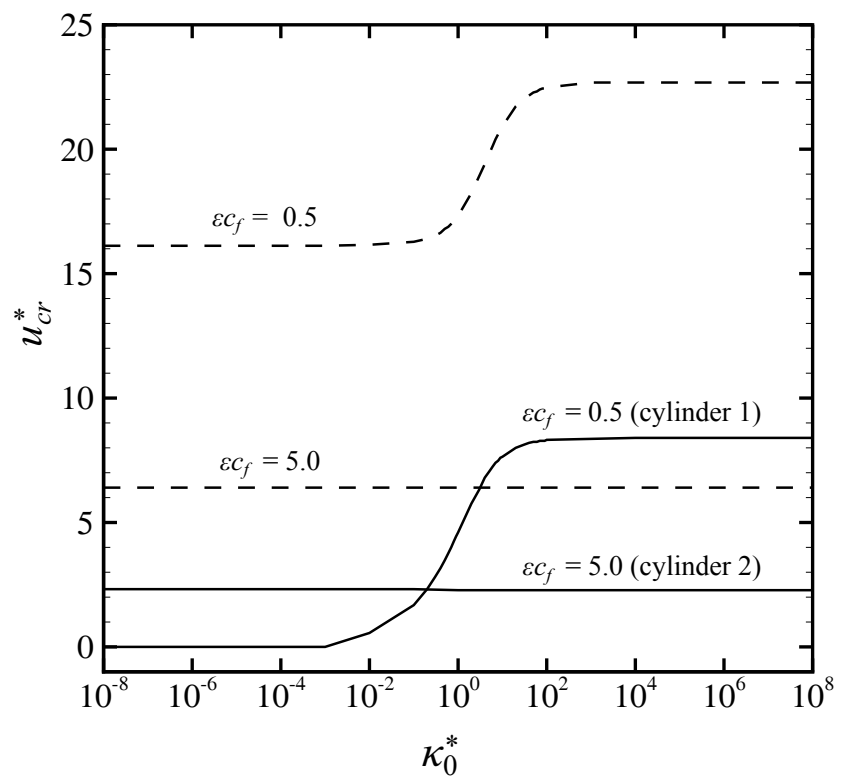

Fig. 4. Variation of the critical flow velocities for static and dynamic instabilities of a pinned-free cylinder (i.e. $u_{c r}^{*}=u_{c r} / \varepsilon^{*}$, where $\varepsilon^{*}=(1 / 2) \varepsilon c_{f}$ ), additionally supported at the pinned end by a rotational spring of stiffness $\kappa_{0}^{*}$, with different values of $\varepsilon c_{f}=\varepsilon c_{T}=\varepsilon c_{N}$ as a function of $\kappa_{0}^{*}$ : 一, divergence; ---, flutter. Other parameters are: $f=0.7, c_{b}=1-f=0.3, \chi_{e}=0.00667$,

$$
\bar{\chi}_{e}=0.00785 \text { and } c=0.0 \text {. }
$$

versa. In contrast, $u_{c r}^{*}$ for the cylinder with $\varepsilon c_{f}=5.0$ (cylinder 2 , for short) is independent of $\kappa_{0}^{*}$. In other words, increasing the stiffness of the rotational spring does not improve stability of cylinder 2 . It is also seen that for very low values of $\kappa_{0}^{*}$, cylinder 1 loses stability earlier than cylinder 2 , whereas for large values of $\kappa_{0}^{*}$, cylinder 2 becomes unstable first.

As also shown in Fig. 4, for cylinder 1, as $\kappa_{0}^{*}$ takes on very small values (i.e. the system approaches a pinned-free cylinder), $u_{c r}^{*}$ for the first instability approaches zero. This, in fact, corresponds to a rigid-body instability, called stationary yawing, which according to linear theory, manifests itself as a divergent non-oscillatory deviation from the position of rest, with or without flexing (for details refer to [9, Chapter 8]). This instability has been referred to as 'divergence' in Fig. 4 for the sake of convenience.

Fig. 5 shows the modal shapes of the unstable modes of cylinders 1 and 2 for different values of $\kappa_{0}^{*}$ (i.e. $\kappa_{0}^{*}=10^{-8}, 1,10$ and $10^{8}$ ). Subfigures (a)(d) show the stationary yawing/divergence mode shape of cylinder 1 , while subfigures (e)-(h) show a cycle of flutter motion of cylinder 1, reconstructed at $u=1.01 u_{c f}$, where $u_{c f}$ represents the threshold of flutter. It is seen from these figures that, as $\kappa_{0}^{*}$ is increased from $10^{-8}$ to $10^{8}$, the modal shape of 


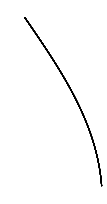

e

(0)

$\hat{e}$

ฮิ

$\gamma$

$\Theta$

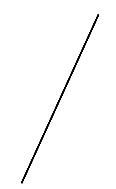

త

e

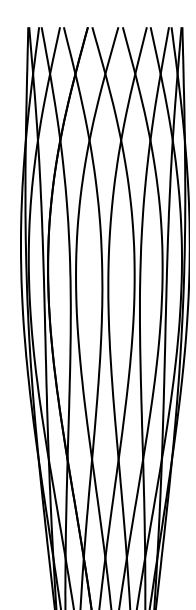

to

。

密

永亯

पै II

芯 芯芯

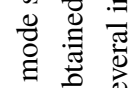

$\begin{array}{lll}0 & 0 & 0 \\ 0 & 0 & 0 \\ 0 & 0 & 0\end{array}$

总 离

章

章苍

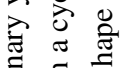

을. $\cong$

荧总

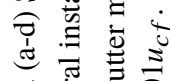

*⿻一丿𠃌

क

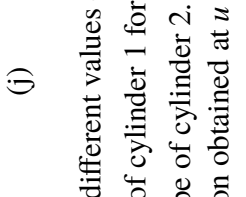

ๆ

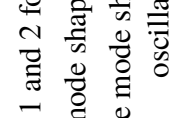

ज)

式壱

苍突

पै

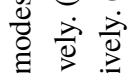

寻

苟范

$\infty 0^{\circ} \infty$

궁 च

远气

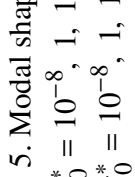

oi $* 0 * 0$ 
the first unstable mode changes gradually from a skewed rigid body to a rigid body involving flexing and then to a buckled shape. Also, variation in the flutter mode shape, especially over the first half of the cylinder length, as $\kappa_{0}^{*}$ is varied, is evident from the figures. On the other hand, subfigures (i) and ( $j$ ) show, respectively, the divergence mode shape and a cycle of flutter motion of cylinder 2 for $\kappa_{0}^{*}=1$. In fact, it was found that the modal shapes of the unstable modes of cylinder 2 are independent of $\kappa_{0}^{*}$ and therefore, they are given in Fig. 5 for a single value of $\kappa_{0}^{*}$. Unlike the modal shapes of cylinder 1 , those of cylinder 2 show that the deformation is limited to a small region close to the downstream end of the cylinder; this dynamical feature of very slender cylinders was discovered previously (see, e.g. $[11,14,15]$ ).

\subsection{The effect of the shape of the end-piece on the critical flow velocities and the modal shapes}

Fig. 6 shows the variation of $u_{c r}^{*}$ for a pinned-free cylinder, additionally supported at the pinned end by a rotational spring of stiffness $\kappa_{0}^{*}$ and fitted at the free end by different end-pieces, as a function of $\kappa_{0}^{*}$. The different values of $f$ considered in Fig. 6, i.e. $f=0.4,0.7$ and 1.0, correspond, respectively, to

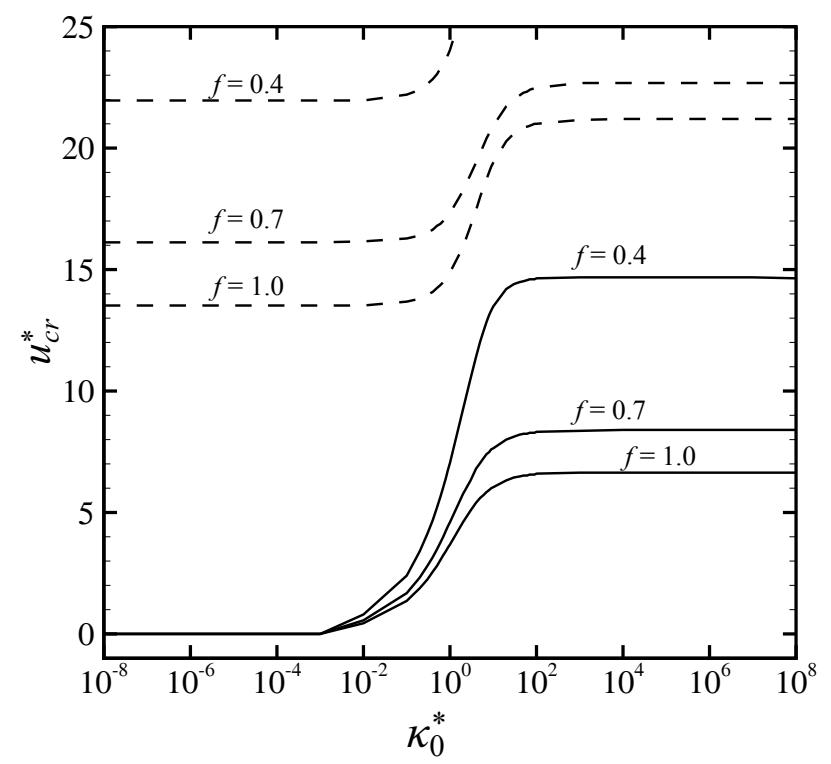

Fig. 6. Variation of the critical flow velocities for static and dynamic instabilities of a pinned-free cylinder (i.e. $u_{c r}^{*}=u_{c r} / \varepsilon^{*}$, where $\varepsilon^{*}=(1 / 2) \varepsilon c_{f}$ ), additionally supported at the pinned end by a rotational spring of stiffness $\kappa_{0}^{*}$, with different end-pieces as a function of $\kappa_{0}^{*}$ : - , divergence; ---, flutter. Other parameters are: $\varepsilon c_{T}=\varepsilon c_{N}=0.5, c_{b}=1-f, \chi_{e}=0.00667, \bar{\chi}_{e}=0.00785$ and $c=0.0$. 
a fairly blunt, well streamlined and perfectly streamlined end-piece. It is noted that for all the three end-pieces, the form drag coefficient over the end-piece, $c_{b}$, is assumed to be related to $f$ as $c_{b}=1-f$.

As seen from the figure, for all values of $\kappa_{0}^{*}$, as $f$ is decreased from 1.0 to 0.4 (i.e. the end-piece becomes less streamlined), $u_{c r}^{*}$ for both divergence and flutter increases, meaning that the cylinder becomes more stable. The only exception occurs for very low values of $\kappa_{0}^{*}$ (i.e. $\kappa_{0}^{*}<10^{-2}$ ), where divergence (precisely speaking, stationary yawing) occurs at $u_{c r}^{*}=0^{+}$, independently from $f$.

Thus, by choosing a reasonably blunt end-piece one can significantly improve stability of the system. In fact, making the end-piece less streamlined has a twofold effect: the transverse force (lift) acting on the end-piece $\left(f F_{A}\right)$ decreases, while the drag force $\left(F_{T D}\right)$ and as a result the induced tension increases, and both of these changes have a stabilizing effect.

Fig. 7 shows the flutter mode shape of a cylinder with a relatively blunt and a perfectly streamlined end-piece, for different values of $\kappa_{0}^{*}$. From this figure and Fig. 5(e-h), which is for the cylinder with a relatively streamlined end-piece, it is found that the flutter mode shape is generally dependent on the shape of the end-piece. On the other hand, the modal shapes of divergence of cylinders with $f=0.4$ and $f=1.0$ were not shown in Fig. 7, as they were generally similar to those in Fig. 5(a-d).

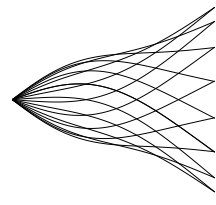

(a)

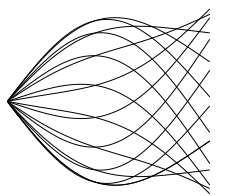

(e)

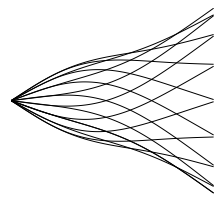

(b)

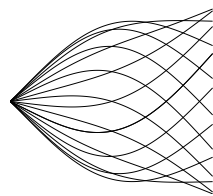

(f)

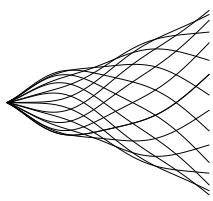

(c)

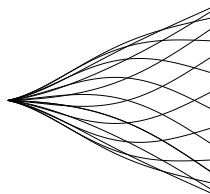

(g)

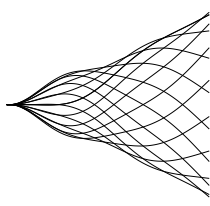

(d)

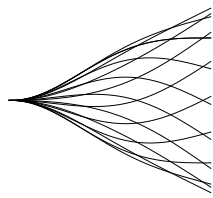

(h)

Fig. 7. Modal shapes of the unstable modes of a pinned-free cylinder, additionally supported at the pinned end by a rotational spring of stiffness $\kappa_{0}^{*}$, for different values of $\kappa_{0}^{*}$. (a-d) Flutter mode shape of the cylinder with a relatively blunt end-piece $(f=0.4)$ for several instants in a cycle of oscillation obtained at $u=1.01 u_{c f}$, for $\kappa_{0}^{*}=10^{-8}, 1,10$ and $10^{8}$, respectively. (e-h) Flutter mode shape of the cylinder with a perfectly streamlined end-piece $(f=1.0)$ for several instants in a cycle of oscillation obtained at $u=1.01 u_{c f}$, for $\kappa_{0}^{*}=10^{-8}, 1,10$ and $10^{8}$, respectively. 


\title{
4. Concluding remarks
}

In this paper, the equation of motion for a flexible, slender cylinder supported only by a translational and a rotational spring at the upstream end and subjected to axial flow was presented. For a typical cylinder (i.e. not a very slender cylinder) with a very stiff translational spring, it was found that at low flow velocities, stationary yawing or divergence may occur, depending on the rotational stiffness, while at higher flows, flutter may arise; moreover, the critical flow velocities for these instabilities and their associated modal shapes were found to be dependent on the rotational stiffness. In contrast, for a very slender cylinder, divergence is the only form of instability at low flow velocities; moreover, the critical flow velocities and the modal shapes of the unstable modes were found to be almost independent of the rotational stiffness. It was also found that a reasonably blunt end-piece can significantly increase the critical flow velocities and thus stabilize the system. The flutter mode shape was found to be dependent on the shape of the end-piece, while the divergence mode shape was weakly dependent on the shape of the end-piece.

\section{Acknowledgements}

The author would like to greatly thank Prof. M. P. Païdoussis and Prof. A. K. Misra for their comments on the short version of this paper presented at the 25th Canadian Congress of Applied Mechanics (CANCAM 2015). Also, the services by the staff and students of Simon Fraser University are sincerely acknowledged, as the most part of this research was carried out while the author was visiting this school.

\author{
Manuscript received by Editorial Board, November 14, 2015; \\ final version, May 26, 2016.
}

\section{References}

[1] W.R. Hawthorne. The early development of the Dracone flexible barge. Proceedings of the Institution of Mechanical Engineers, 175:52-83, 1961.

[2] M.P. Païdoussis. Dynamics of flexible slender cylinders in axial flow. Part 1. Theory. Journal of Fluid Mechanics, 26:717-736, 1966.

[3] M.P. Païdoussis. Dynamics of flexible slender cylinders in axial flow. Part 2. Experiments. Journal of Fluid Mechanics, 26:737-751, 1966.

[4] M.P. Païdoussis. Stability of towed, totally submerged flexible cylinders. Journal of Fluid Mechanics, 34:273-297, 1968.

[5] G.S. Triantafyllou and C. Chryssostomidis. Analytic determination of the buckling speed of towed slender cylindrical beams. ASME Journal of Energy Resources Technology, 106:246249, 1984.

[6] G.S. Triantafyllou and C. Chryssostomidis. Stability of a string in axial flow. ASME Journal of Energy Resources Technology, 107:421-425, 1985. 
[7] A.P. Dowling. The dynamics of towed flexible cylinders. Part 1: Neutrally buoyant elements. Journal of Fluid Mechanics, 187:507-532, 1988.

[8] A.P. Dowling. The dynamics of towed flexible cylinders. Part 2: Negatively buoyant elements. Journal of Fluid Mechanics, 187:533-571, 1988.

[9] M.P. Païdoussis. Fluid-Structure Interactions: Slender Structures and Axial Flow., volume 2. Oxford: Elsevier Academic Press, 2004.

[10] Y. Modarres-Sadeghi, M.P. Païdoussis, and C. Semler. A nonlinear model for an extensible slender flexible cylinder subjected to axial flow. Journal of Fluids and Structures, 21:609-627, 2005.

[11] E. de Langre, M.P. Païdoussis, O. Doaré, and Y. Modarres-Sadeghi. Flutter of long flexible cylinders in axial flow. Journal of Fluid Mechanics, 571:371-389, 2007.

[12] S. Rinaldi and M.P. Païdoussis. Theory and experiments on the dynamics of a free-clamped cylinder in confined axial air-flow. Journal of Fluids and Structures, 28:167-19, 2012.

[13] M. Kheiri, M.P. Païdoussis, and M. Amabili. A nonlinear model for a towed flexible cylinder. Journal of Sound and Vibration, 332:1789-1806, 2013.

[14] M. Kheiri, M.P. Païdoussis, M. Amabili, and B.I. Epureanu. Three-dimensional dynamics of long pipes towed underwater. Part 1: The equations of motion. Ocean Engineering, 64:153-160, 2013.

[15] M. Kheiri, M.P. Païdoussis, M. Amabili, and B.I. Epureanu. Three-dimensional dynamics of long pipes towed underwater. Part 2: Linear dynamics. Ocean Engineering, 64:161-173, 2013.

[16] M. Kheiri, M.P. Païdoussis, and M. Amabili. An experimental study of dynamics of towed flexible cylinders. Journal of Sound and Vibration, 348:149-166, 2015.

[17] M. Kheiri and M.P. Païdoussis. Dynamics and stability of a flexible pinned-free cylinder in axial flow. Journal of Fluids and Structures, 55:204-217, 2015.

[18] J.-L. Lopes, M.P. Païdoussis, and C. Semler. Linear and nonlinear dynamics of cantilevered cylinders in axial flow. Part 2: The equations of motion. Journal of Fluids and Structures, 16:715-737, 2002.

[19] M. Amabili. Nonlinear Vibrations and Stability of Shells and Plates. Cambridge University Press, 2008.

[20] G.I. Taylor. Analysis of the swimming of long and narrow animals. Proceedings of the Royal Society (London), A214:158-183, 1952.

[21] M.J. Lighthill. Note on the swimming of slender fish. Journal of Fluid Mechanics, 9:305-317, 1960.

[22] M. Kheiri, M.P. Païdoussis, G. Costa Del Pozo, and M. Amabili. Dynamics of a pipe conveying fluid flexibly restrained at the ends. Journal of Fluids and Structures, 49:360-385, 2014.

\section{Dynamika i stabilność giętkiego, smukłego cylindra, z jednym końcem umocowanym sprężyście a drugim swobodnym, w warunkach przepływu osiowego}

Streszczenie

W pracy zastosowano równania Lagrange'a i metodę Ritza by uzyskać równania ruchu giętkiego, smukłego cylindra poddanego działaniu przepływu osiowego. Cylinder umocowany od strony dopływu za pomocą sprężyn translacyjnej i rotacyjnej ma drugi koniec swobodny ze zbieżną końcówką. Równanie ruchu jest rozwiązane numerycznie dla systemu, w którym sprężyna translacyjna ma nieskończoną sztywność i zachowuje się jak kołek, podczas gdy sztywność sprężyny rotacyjnej jest generalnie różna od zera. Opisano krótko dynamikę takiego systemu ze sprężyną rotacyjną o średniej sztywności. Ponadto, badano zależności między długością cylindra i kształtem końcówki a krytycznymi prędkościami przepływu i rozkładami modów niestabilnych. 